\title{
A humanização na saúde como instância libertadora
}

\section{The humanization in health as a freedom instance}

Alberto Olavo Advincula Reis

Professor Doutor do Departamento de Saúde materno-infantil, FSP, USP.

E-mail: albereisळusp.br

Isabel Victoria Marazina

Mestre em Psicologia Clínica pela PUC-SP, Psicanalista Institucional, membro do Comitê de Humanização do Ministério da Saúde, Brasil, gestão Ministro José Serra.

E-mail: imarazinaळuol.com.br

Paulo Rogério Gallo

Professor Doutor do Departamento de Saúde materno-infantil, FSP, USP.

E-mail: prgalloळusp.br

\section{Resumo}

O texto discute a política de Humanização em Saúde do ponto de vista da lógica que a sustenta, em particular como uma ação da singularidade dos atores implicados no processo de produção da Saúde. A análise desenvolvida aponta para o fato de que as práticas de atenção à saúde, quando de acordo com os cânones da lógica utilitária, refletem não apenas uma ordem autoritária, como produzem sujeitos cerceados, fragmentados e incapazes. A humanização em Saúde é considerada uma possibilidade política de se alterar essa lógica e de instaurar, no interior das instituições, espaços de liberdade capazes de acolher, amparar, sustentar e dar significado à presença e às ações de profissionais de saúde, gestores e pacientes, ao considerar suas dimensões subjetivas e singulares.

Palavras-chaves: Humanização em saúde; Subjetividade; Saúde Mental. 
Abstract

The text presents the politics of Humanization in Health from the point of view of the logic that gives support to it, i.e., as an action of the actors' singularity implicated in the process of Health production. The analysis points to the fact that the practices devoted to health attention, when in consonance with the prescriptions of the utilitarian logic reflect an authoritarian order, but also produce reduced, fragmented and incapacitated subjects. The humanization in the field of Health is considered as a political possibility of altering that logic and of establishing within the institutions spaces of freedom capable to hold, to aid, to sustain and to give a different meaning to the presence and professionals providing health actions, as well as managers and patients, considering their subjective and singular dimensions.

Key Words: Humanization in Health; Subjectivity; Mental Health.

\section{A humanização em Saúde}

O processo de humanização da Saúde tem suas origens nos movimentos de reformas sanitárias, nas Conferências de Saúde e nos grupos militantes voltados à ações em prol do desenvolvimento de uma consciência cidadã e cujas atuações se tornaram, a partir da década de 1980, gradativamente influentes, estruturadas e articuladas. Na realidade, a reordenação do conceito de saúde, pedra de toque do movimento de reforma sanitária, incorpora, entre seus determinantes, as condições de vida e desloca no sentido da comunidade a assistência médico-hospitalar como diretriz da atenção à saúde (Queiróz, 1992).

A institucionalização desse processo, com a Constituição de 1988 e a estruturação do SUS, inaugurou o reordenamento teórico, paradigmático e operacional da Saúde que a levou a ser compreendida no âmbito da Segurança Social. Nesse contexto, a idéia de Humanização passou a ser entendida como "a valorização dos diferentes sujeitos implicados no processo de produção de Saúde" (SUS/PNH 2004). Destaca-se, na definição, que o esforço de humanização é concebido como um aporte de valor positivo alocado ao sujeito implicado na produção da Saúde, embora, no entendimento comum, não seja raro que designe o usuário ou cliente externo como principal, quando não único, alvo da humanização.

Quaisquer que sejam as antropologias que sejam consideradas na sustentação da noção de sujeito, temse que no âmbito da humanização em saúde, ela se plasma em uma dimensão que transcende a idéia de pessoa, funcionário, servidor ou usuário, aproximando-se da noção de instância ou de lugares institucionais. Isso, por outro lado, não significa que ela venha ignorar a dimensão particular dos sujeitos. Ao contrário, pelo fato da humanização em saúde definir-se pelo valor atribuído ao esforço dos sujeitos na produção da saúde, quando se contemplam a autonomia, o protagonismo, a co-responsabilidade e a vinculação das instâncias, põe em evidência (dada a noção de valor) a dimensão da subjetividade e da singularidade. Categorias como vínculo, responsabilidade, autonomia destacam a ênfase na subjetividade, posto que não são categorias do mundo inerte, mas próprias do sujeito. Este é o cerne da questão. 
No plano de sua realização político-institucional, a humanização recebeu acolhimento, na gestão do presidente Fernando Henrique Cardoso, com a implantação do Programa Nacional de Humanização, e continuidade e incremento, no Governo do Presidente Lula, quando o Programa foi alçado a uma dimensão de Política Nacional de Humanização. Esse passo não foi sem importância, como se refere explicitamente o Ministro Humbert Costa: "para isto estamos construindo uma política que nomeamos Política Nacional de Humanização da Atenção e Gestão no Sistema Único de Saúde Humaniza - SUS” (Brasil-MS, 2004, p. 9).

Contudo, a despeito de sua maior visibilidade de esforço voltado a sua implementação bem como do grau de realidade envolvido em suas propostas e do compromisso oficial traduzido em empenho de organização e formalização, a política de humanização encontra-se longe de constituir-se em realidade. Em seus esforços de implementação não raro observamse desequilíbrios, que ocorrem até como conseqüência da falta de assistência endêmica instalada no setor Saúde. O fato é que a ênfase dada ao empenho de humanização na saúde pende, amiúde, para o lado das necessidades imediatas do usuário ou cliente externo, de acordo com uma lógica dicotômica de confrontação alimentada por uma tradição paternalista, cujo efeito mais direto se traduz na opacidade dos serviços. Nesse caso, é a própria essência da política de humanização que se vê comprometida nessa má ponderação, uma vez que se alteram os preceitos de co-responsabilidade, vinculação solidária e participação coletiva no processo de gestão. A integralidade, numa acepção mais ampla e livre, implica mais do que uma lógica definidora do objeto saúde entendido como entidade bio-psicosocial, mas uma compreensão do próprio processo de produção de saúde e de seus sujeitos. 0 próprio Ministério da Saúde enfatiza essa concepção integral das instâncias presente na política de humanização quando salienta que parte importante do encaminhamento do processo de humanização apóia-se "no estilo de gestão e na estrutura de poder das instituições de saúde", uma vez que estilo e estrutura "determinam e condicionam posturas e comportamentos relativos aos vínculos profissionais de saúde e usuário, bem como entre os profissionais de saúde entre si” (Cartilha PNH, 2004).

\section{o Modelo da Saúde Mental e a Sin- gularização do Acontecer Psíquico}

As iniciativas de humanização, encaminhadas como programa e, em seguida, como política, receberam influências diversas. Não cabe aqui historiá-las. Uma delas foi particularmente importante e, se é salientada, é porque trouxe de imediato à baila a questão da subjetividade dos sujeitos e pôs em relevo, como condição precípua de sua realização, a questão da reflexão das relações dos profissionais no interior das instituições de saúde. Trata-se do processo de humanização que incidiu inicialmente num setor mais específico, menos abrangente, que é a área de Saúde Mental.

0 modelo da saúde mental se desenha no discurso da medicina desde que, em 1948, a recém fundada Organização Mundial da Saúde passou a promover um novo conceito de saúde, transcendendo as dimensões exclusivas da saúde biológica. Nesse novo conceito não se tratava mais de se pensar a saúde como ausência de doença ou invalidez, mas de promoção de um estado de bem-estar completo, físico, mental e social. Uma das conseqüências imediatas dessa nova definição foi a substituição do conceito de higiene mental pelo de saúde mental, o que implicou uma mudança substancial de concepção, no rastilho que acompanhou a mudança geral do campo da saúde.

Na América Latina, essa mudança se concretizou no Primeiro Congresso Latino-americano de Saúde Mental organizado no Brasil, em 1954, e no Segundo Congresso, que aconteceu em Buenos Aires, dois anos mais tarde.

0 novo conceito, estreitamente ligado à Declaração Universal dos Direitos Humanos, também nascida em 1948, permitia articular de forma estruturada as disciplinas pertencentes à Saúde Mental às ligadas à Saúde Física. Apesar das críticas que foram formuladas - a posteriori - no sentido de sua generalidade e imprecisão, o novo conceito se legitimou com relativa rapidez dentro do campo médico e da saúde pública. Nesse momento, há de se assinalar que não só o campo da saúde pública era atingido pelo impacto dos movimentos de recomposição da prática médica (Medicina Integral e Medicina Preventiva) como começavam a se gestar os princípios que antecipavam a proposta da Saúde Coletiva, que abriria espaço, a partir 
do segundo quarto do século XX, para o ingresso e contribuições decisivas das Ciências Humanas no campo da Saúde Pública, tal como bem mostrou Birman (1991).

No primeiro caso, o movimento se caracterizou, de acordo com Alvarenga (1984), entre outros aspectos, pela integração do "social" à prática médica, bem como pela "necessidade do descentramento do enfoque biológico[...]” (Donnangelo e col, 1976). Tratou-se, pois, segundo Alvarenga (1976, p. 8o), de uma estratégia que promoveu uma concepção globalizada do objeto individual e tentou recuperar sua totalidade biopsicosocial. No segundo, mais tardio, caracterizado pela proposta de Saúde Coletiva, o conceito de Saúde foi enriquecido pelos aportes das Ciências Humanas, particularmente na incidência de suas críticas ao discurso bio-naturalista que condicionava então a vereda estreita pela qual se considerava a Saúde.

Este remanejamento de paradigmas possibilitou que, a partir daí, se passasse a considerar legitimamente o corpo não apenas como entidade natural, mas como lugar atravessado por desejos e condicionado em seu funcionamento pela vida simbólica. Na esteira desta legitimação, começa a emergir a categoria de "trabalhadores de saúde mental”, já que se faz necessária uma ampliação de categorias profissionais para tratar da saúde psíquica, que até esse momento era patrimônio quase exclusivo do médico, enfatizando prioritariamente a doença e não o sujeito. Já não se fala em trabalhar com a patologia, mas sim a favor do bem-estar.

Assim, percebe-se que o modelo que vai se construindo sob a égide do conceito de saúde mental é um modelo que embora tenha se organizado a partir da Psiquiatria recebeu influências de várias outras disciplinas, com destaque para aquelas pertencentes ao campo das ciências humanas, tais como a psicanálise, a sociologia, a antropologia.

Num plano mais geral, não se pode ocultar o pano de fundo sobre o qual se desenharam as transformações no campo da Saúde. Trata-se, no caso, de um dos acontecimentos políticos mais significativos do século: a Segunda Guerra Mundial. As conseqüências da deflagração do conflito mundial imprimiram a necessidade do resgate dos valores humanos, frente aos horrores dos campos de extermínio e da guerra atômica. Toda uma construção que alicerça o Estado de
Bem-Estar social se originou a partir da tentativa de se criarem novos paradigmas visando evitar a repetição do pior, e a Saúde não se achou excluída desse esforço.

A valorização do conceito de saúde mental veio deslocar a ênfase dada ao discurso médico para uma atenção multidisciplinar, na qual os discursos de diversos saberes pudessem construir uma visão integrada do sujeito em sofrimento, trazendo, desta feita, a um plano primeiro, a sua singularidade e sua subjetividade.

Nesse âmbito, convém assinalar que parte do aporte significativo da psicanálise no remanejamento dos paradigmas da Saúde foi dada pelo conceito de singularização do acontecer psíquico. Vale dizer que enquanto a Psiquiatria procedia pelo estabelecimento da ordenação do mal-estar dentro dos grandes quadros psicopatológicos, a psicanálise propunha uma abordagem singular do paciente, no sentido de considerar a maneira própria pela qual os pacientes conseguiam organizar o seu sofrimento dentro de um sentido possível para eles. Torna-se mais claro que a questão sobre a qual se desenrola o embate não incide sobre o indivíduo, mas sobre a singularidade do sujeito em sua dimensão psíquica.

Alem disso, diversas contribuições oriundas das vizinhanças psicanalíticas, como por exemplo, os trabalhos iniciais de Bion sobre o funcionamento psíquico dos grupos, vieram mostrar que o aspecto da realidade social deveria ser parte incontornável do procedimento diagnóstico e curativo. Assim, no âmbito da Saúde Mental passou-se a incorporar estratégias capazes de entender e atender os aspectos alienantes da realidade social e laboral na qual o paciente encontra-se inserido. Os trabalhos realizados pela psiquiatria sobre os efeitos dos traumas de guerra serviram de importante alicerce para poder realizar essa conexão entre um processo de adoecimento e o meio em que este se realiza.

É verdade, igualmente, que as iniciativas que se desenrolaram no campo da Saúde Mental foram incentivadas pelo fato de ali vicejarem as condições mais deletérias, mais desumanas no campo da Saúde, afetando e brutalizando a todos, clientes internos e externos. Foi nesse elo fraco do Sistema de Saúde que se irrompeu uma das primeiras e mais radicais manifestações em prol da humanização do setor. 0 processo de humanização do setor da Saúde Mental se deu atra- 
vés da batalha antimanicomial, pela extinção dos castigos corporais e mentais disfarçados em técnicas terapêuticas, pelo fim do abuso medicamentoso, pela liberação da palavra e abertura de sua escuta, pelos direitos dos pacientes e, sobretudo, pelo reordenamento das relações dos profissionais de Saúde entre si e de suas relações com os pacientes. As iniciativas no campo da Saúde Mental, que antecipariam o movimento mais geral de humanização da Saúde, se constituíram, antes de tudo, como uma instância de liberação.

Nos anos 70, tornaram-se célebres, sobretudo no Primeiro Mundo, as iniciativas voltadas à prática de análises institucionais e à criação de comunidades terapêuticas em que se processaram as primeiras experiências significativas de relações humanizadas no campo da Saúde. Compreendeu-se, nesse contexto, que as relações desenvolvidas entre os profissionais das Comunidades tinham um efeito direto sobre a saúde dos pacientes. A partir das experiências que se desenrolaram no interior dessas comunidades, entendeu-se de imediato que o desmantelamento do poder institucional, que produzia práticas abusivas e desumanas, passava por discussão e debate, das iniciativas e dos problemas, capaz de envolver, em seus níveis diversos, o conjunto dos sujeitos participantes do processo de produção da Saúde. Fora dessas condições de participação, responsabilidade e interação, os procedimentos de humanização, mesmo tratando-se de iniciativas positivas, quando processados goela abaixo, só mantinham o que aparentemente se queria abolir.

No rastilho disso e fortemente condicionado pelas lutas feministas, o processo de humanização que colocava em questão tanto uma visão naturalista do processo de saúde-doença como o princípio de poder institucional comandando práticas e comportamentos, estendeu-se também em relação às práticas médicas dirigidas à mulher, precipuamente o parto. Daí para frente, a Saúde como um todo se viu atingida por um movimento libertador iniciado nos porões sombrios onde jaziam os dementes.

\section{As Práticas Criam os Sujeitos}

Certamente, o profissional de saúde que trabalha no contexto da rede pública já ouviu falar, até bastante, das iniciativas de humanização. Alguns deles já participaram - e participam - de iniciativas isoladas, bem sucedidas, nos seus locais de trabalho. Geralmente, elas se realizam porque a Direção da instituição demonstra interesse em impulsioná-las.

Muitas vezes, a empreitada toma o viés de uma melhoria nas condições do espaço físico e de circulação dentro dos prédios, outras vezes é relativa à instalação de diversos grupos de acolhimento para pacientes com patologias específicas ou ainda trabalhos sobre aleitamento e orientação do parto. Também não é raro assistir à promoção de uma série de treinamentos, dirigidos aos funcionários encarregados de recepção ou da enfermagem, sobre a melhor modalidade de atendimento dos pacientes e, voilà! O projeto de humanização está em andamento.

Sem nenhuma intenção de se desvalorizar tais medidas, que em muito ajudam os pacientes que circulam pelas instituições de saúde, faz-se, entretanto, necessária uma análise mais aprimorada tendo-se em conta o contexto institucional na qual elas se desenvolvem.

Como ponto de partida, convém resgatar a famosa frase pronunciada pelo velho aristocrata do filme de Visconti, baseado no romance de Tomasi di Lampedusa, "Il Gattopardo", que questionado em relação às mudanças, que se anteviam na sociedade italiana com a ascensão da burguesia, replicava que: ...”se faz necessário que algo mude, para que o essencial continue intato". Sob que condições a humanização na Saúde pode servir ao conservadorismo? Em suma, qual seria esse "essencial" que necessita ser protegido?

Ora, pode-se perceber nas instituições de saúde, tanto no nível dos complexos hospitalares como em postos ou centros mais simples, a existência organizadora de uma certa lógica- "árvores de lógicas", na expressão de Baremblitt (1986, p 219), ramificações de sentidos- que continua sendo tributária do discurso da medicina. Esse discurso médico é aquele que dá ênfase e promove a relação curativa e assistencial, estimando como menores as ações que possam advir da prevenção e elidindo, na consideração diagnóstica, os fatores que possam advir do estatuto socioeconômico ou subjetivo, singular, do paciente atendido.

Esse tipo de lógica, que se poderia denominar instrumental, estende-se como pano de fundo da prática da medicina. Foi somente em tempos recentes, da segunda metade do século XX em diante, que tal prática passou a ser alterada pelas contribuições de numero- 
sas disciplinas pertencentes a outros campos epistemológicos, conforme já mencionado, de forma a poder abrir novos espaços para outras formas de tratamento. Isto não significa que, a velha lógica, a título de instituído fundador, não reapareça de forma às vezes muito pouco consciente nas práticas cotidianas dos agentes de Saúde, fazendo resistência às intenções de maior abertura preconizadas, no plano ideológico, pelos próprios agentes. Neste particular, entende-se que toda ideologia porta tanto aspectos conscientes quanto inconscientes, que se encontram numa permanente tensão, à medida que as práticas que ela propõe acham espaço para operar na realidade.

Michel Foucault através de sua obra, dedicada à observação da história da medicina, demonstra que a predominância do discurso científico - do qual a medicina é uma das suas filhas diletas - vai produzindo uma prática que se afasta cada vez mais da singularidade para se alicerçar numa consideração da generalidade do "caso", excluindo o sujeito como possível coresponsável no processo de sua cura, privando-o de fala ou decisão sobre seu corpo, e colocando o profissional médico como possuidor de uma verdade inquestionável sobre a doença.

A humanização em Saúde aparece, desta feita, como uma intervenção nessa lógica e finda por questionar paradigmas que sustentam essa forma de ver o mundo. Tal intervenção e tal questionamento têm, amiúde, por efeito, provocar fortes resistências nos sujeitos que compartilham da lógica instrumental. Freud ensinou que toda forma de ver o mundo se sustenta para cada sujeito em poderosas moções inconscientes. Essa idéia, apropriada e largamente desenvolvida pelas correntes institucionalistas, ajuda a compreender, em parte, a forte inércia que acompanha todo processo de mudança. A relação entre uma visão de mundo e os sujeitos que a sustentam não opera no sentido de mão única. A visão de mundo, e as práticas que dela se desdobram, também produzem uma subjetividade específica, criam sujeitos que apóiam sua identidade nessa visão. 0 ditado popular o expressa de forma clara: "o hábito faz o monge".

Em muitos momentos das discussões com os profissionais da saúde, em relação à humanização, essa resistência aparece claramente, travestida de diferentes roupagens, que pode ser bem apreendida por algumas frases colhidas em um dos processos de interven- ção em humanização na saúde:

"Além de ganhar mal e de trabalhar feito um escravo, vou ter de levar em conta o que o paciente tem a dizer... e como fazer com a famosa produtividade se fico horas com um paciente?"

"Um médico tem de saber diagnosticar a doença... essas coisas da personalidade deixo para o psicólogo... se o paciente se inquieta, chamo o psicólogo e eles que se entendam"

"Dentro do meu hospital quem decide como se trata sou eu, que sei das dificuldades de conseguir pessoal e recursos. Afinal, muito se fala de tratar bem os pacientes, mas, e aos médicos e as enfermeiras, quem olha por eles?"

Pode-se pensar que ali se manifestam sujeitos que foram se produzindo nas práticas que eles desenvolvem ou, no mínimo, reforçados por elas em traços que lhes são próprios. Não se pode esquecer, a respeito desse propósito, que nossa cultura é muito permeável a um estilo de gestão autoritário, tanto na esfera pública quanto na privada, que gera uma constante confusão entre o espaço próprio e o espaço coletivo.

Mas, o melhor diagnóstico encontra-se no Documento Básico para Gestores e Trabalhadores do SUS, sobre Política Nacional de Humanização, que elenca um certo número de desafios que o SUS enfrenta na sua implantação, (Brasil-MS, 2004. p.13)

Fragmentação do processo de trabalho e das relações entre os diferentes profissionais";

Fragmentação da rede assistencial dificultando a complementaridade entre a rede básica e o sistema de referência;

Precária interação entre as equipes e despreparo para lidar com a dimensão subjetiva nas práticas de atenção; Sistema público de saúde burocratizado e verticalizado;

Baixo investimento na qualificação dos trabalhadores, especialmente no que se refere à gestão participativa e ao trabalho de equipe;

Poucos dispositivos de fomento à co-gestão e à valorização e inclusão dos gestores, trabalhadores e usuários no processo de produção da saúde;

Desrespeito aos direitos dos usuários;

Formação dos profissionais distantes do debate e formulação da política de saúde; 
Controle frágil dos processos de atenção e gestão do SUS;

Modelo de atenção "centrado na relação queixa-conduta”.

Essas práticas, mais do que ações condenáveis e criticáveis, aparecem como elementos institucionais produtores de sujeitos fragmentados; burocratizados na sua relação com os usuários; individualistas e distantes da percepção da sua própria importância para a sustentação da política de saúde, na qual se acham imersos. A apatia e a indiferença são majoritariamente efeitos da violência e do desamparo, do cerceamento que uma política de saúde como a descrita os submete no seu cotidiano.

É importante, ainda, assinalar que, embora a discursividade médica, com sua lógica centrada no profissional, na ação curativa e focada na queixa, produza efeitos presentes numa prática de saúde desumanizada, não é possível, contudo, atribuir-lhe uma total responsabilidade na manutenção das condições de precariedade do sistema de atenção à saúde. O essencial da desumanização reside no descaso histórico e politicamente produzido pelos sucessivos governos, em uma ordem maior, cuja análise não cabe desenvolver aqui. Outros países, aplicando corretamente o mesmo modelo, conseguem condições razoáveis, dentro do campo da assistência.

Mas, retornando ao particular da questão da humanização na saúde, entende-se que uma política de humanização efetiva só pode funcionar se compreendida como uma verdadeira intervenção institucional na lógica instalada dentro do sistema de saúde, e assim como nos diferentes níveis de efeitos que ela comporta. Para isto, essa intervenção não pode ser menos que uma política, isto é, um dispositivo de amplo alcance sustentado pela maior instância de gestão do Estado. 0 fato de a humanização ter sido apresentada, até recentemente, como um programa e não como uma política, limitava suas possibilidades de autorização - e portanto de intervenção- nos espaços onde era proposta.

\section{Desafios e Possibilidades da Huma- nização}

A compreensão de que a Humanização pode ter uma incidência sobre a lógica do atual sistema de organi- zação das práticas de saúde, por tudo o que foi expresso, não implica a cegueira face às dificuldades da tarefa nem da necessidade de firmá-la como um processo de longo alcance, que não sofra deturpações de acordo com a vontade do governante do momento. Decorre daí, a importância de se estabelecer a Humanização como política de amplo alcance dentro do campo nacional da saúde.

Essa política, se continuada, deve contemplar alguns aspectos concretos que aparecem como fundamentais. Assim, em primeira instância, deve ser entendido que as instituições de formação profissional são partes imprescindíveis desse processo, uma vez que são os grandes aparelhos formadores que possibilitam a transmissão não somente da técnica e da informação quanto da ideologia que sustenta sua operacionalização concreta. Um dos grandes desafios da Humanização é incidir na reformulação curricular, de forma a permitir uma visão mais abrangente do processo de prevenção e assistência, que toma o nome de “clínica ampliada". Ampliada, na medida em que se entende qualquer procedimento clínico como produtor de subjetividade, sendo, portanto, uma ferramenta importantíssima tanto na formação de cidadãos ativos e responsáveis, quanto para propor lugares alternativos aos da passividade e inércia presentes no processo de adoecimento e cura. Isto constitui uma reviravolta de porte, não somente para os pacientes, instados a "não incomodar o médico", quanto para os profissionais, que foram ensinados a não escutar $o$ paciente, na medida em que ele próprio "não sabe" do seu mal-estar.

Outro espaço onde esta mudança enfrenta uma batalha cotidiana é o da gestão das práticas. Todo um sistema de pensamento está plasmado num sistema de gestão, que abrange desde a maneira pela qual o profissional se posiciona até a elaboração de planejamentos institucionais, locais e gerais. A incorporação efetiva dos organismos, já existentes, de participação da comunidade, assim como as criações de novos dispositivos, surgem como formas decisivas de intervir na gestão institucional dos problemas, de realizar a humanização da saúde como instância de libertação.

$\mathrm{Na}$ verdade, tratam-se de diferentes efeitos de um mesmo processo. Contudo, um dos mais importantes aparece como sendo o espaço do próprio profissional da saúde. Na medida em que a política de humaniza- 
ção passa a ser vivida, prioritariamente, como uma perda do poder de decisão e uma delimitação de sua autonomia, o profissional de saúde a ela resistirá, com maior ou menor intensidade.

A política de Humanização em Saúde deve ser um instrumento de transferência de um poder centralizado, que envolve naturalmente risco e responsabilidade, para um poder compartilhado, no qual diferentes instâncias - profissionais, pacientes e gestores possam sustentar o delicado processo de prevenção e assistência.

Os elevados índices de adoecimento daqueles que devem dar conta de demandas de altíssima complexidade com precários recursos materiais e subjetivos, como mostrado, por exemplo, por Kogima (2004), em seu estudo sobre a percepção da depressão puerperal pelas enfermeiras de uma UBS em São Paulo, ou o de Moreno e cols. (2002), sobre a comunicação do resultado de sorologia positiva de Aids, são mostras correntes dos efeitos dessa concentração de poder que se sustenta na lógica instrumental. Ora, uma política de humanização consistente não é nada mais - e nada menos - que uma rede de amparo e contenção para os pacientes e para os profissionais que nela se acham implicados e, nesta exata medida, surge como uma instância de libertação real de seus sujeitos.

\section{Referências}

ALVARENGA, A. T. de. O conceito de risco na área materno-infantil: considerações teórico-metodológicas e de aplicação. São Paulo, 1984. Tese (Doutorado em Saúde Pública) - Faculdade de Saúde Pública, Universidade de São Paulo.

BAREMBLITT, G. Grupos: teoria e técnica. Rio de Janeiro, Graal; 1986, 219 p. (Biblioteca de Psicanálise e Sociedade, 1).
BIRMAN, J. A physis da saúde coletiva. Revista Saúde Coletiva. 1: 7-11, 1991.

BRASIL. Ministério da Saúde. Política Nacional de Humanização: documento base para gestores e trabalhadores do SUS/Ministério da Saúde. Brasília, 2004. 54 p.

BRASIL. Ministério da Saúde. Secretaria de Assistência à Saúde. Programa Nacional de Humanização de Assistência Hospitalar. Brasília, 2002. 50 p.

CAPRARA A. e FRANCO A. L. S. A relação paciente-médico: para uma humanização da prática médica. Cadernos de Saúde Pública, vol.15, n.3, p. 647-654, jul./set. 1999.

DONNANGELO M. C. F. Saúde e Sociedade. São Paulo, Duas Cidades, 1976.

FERNANDES J. C. L. A quem interessa a relação médico paciente? Cadernos de Saúde Pública, jan./mar. 1993, vol.9, n.1, p. 21-27.

FOUCAULT M. Microfísica do poder. Rio de Janeiro, Graal, 1995. 295 p. (Biblioteca de Filosofia e História das Ciências, 7).

FOUCAULT M. O nascimento da clínica. Rio de Janeiro, Forense Universitária; 1994. 241 p.

KOGIMA, E. O. O entendimento dos enfermeiros de uma Unidade Básica de Saúde acerca da depressão puerperal, São Paulo, 2004. Dissertação (Mestrado em Saúde Pública) - Faculdade de Saúde Pública, Universidade de São Paulo.

MORENO, D. M. F. C., REIS, A. O. A. O momento da comunicação do resultado sorológico para o HIV sob a ótica winnicottiana. In: Pulsional-Revista de Psicanálise. São Paulo, v. XV (156): 20-5, 2002.

QUEIROZ, M.S. e VIANNA A.L. Padrão de política estatal em saúde e o sistema de assistência médica no Brasil atual. Revista de Saúde Pública, São Paulo, v. 26, n.2, p.132-140, abr. 1992. 